\title{
El Somatén. Su formación en Melilla (1923-1929)
}

\section{Francisca González Sorroche}

\section{1.-INTRODUCCION}

La institución del Somatén, de honda raigambre en Cataluña, fue extendida a toda España por Real Decreto de 20 de septiembre de 1923. Primo de Rivera, Presidente del Directorio tras el golpe de Estado del 13 de septiembre había sido hasta entonces Capitán General de Cataluña.

El Somatén habia adquirido ya para entonces un matiz conservador, que se acentuó durante la época de la dictadura del marqués de Estella; ello trajo consigo la inmediata disolución de esta institución al proclamarse en España la Segunda República en 1931. Es de destacar que el Somatén fuera de Cataluña aparece como algo postizo e impuesto. La escasa o nula participación efectiva en la marcha de los acontecimientos políticos y sociales y su total supeditación al ejército hace pensar que fue implantado en toda España con el fin de organizar grupos armados totalmente adictos al régimen, condición ésta indispensable para ser somatenista y, por otra parte, para fomentar un ambiente de exaltación de los valores castrenses dentro de la población civil. Es decir, por motivos psicológicos y propagandísticos, más que verdaderamente efectivos.

A través de la documentación existente se desprende que en Melilla la vida del Somatén fue lánguida a excepción de los momentos de exaltación del Régimen o de exaltación patriótica, desfiles, homenajes, etc., donde siempre estaba presente el cuerpo de somatenes del cual se hacen encendidos elogios en la prensa local.

Para la elaboración de este trabajo y en cuanto se refiere concretamente a Melilla, me he servido fundamentalmente del periódico local El Telegrama del Rif, complementado por Anuarios, Actas Municipales y bibliografia que se recoge a pie de página.

\section{2.-DEFINICION Y TRAYECTORIA HISTORICA DEL SOMATEN}

\section{1.-Definición}

Según el artículo primero del Reglamento de 1890 , el Somatén tiene por objeto "asegurar y conservar la tranquilidad del pais, hacer respetar las leyes, las autoridades legalmente constituidas y perseguir hasta su captura o completo exterminio a toda partida latro-fracciosa que bajo una bandera cualquiera intente turbar la paz 
pública, a los ladrones y malhechores que traten de ejercer sus rapiñas o procuren refugio en el territorio y a toda persona reclamada por la justicia (1).

\section{2.- Trayectoria histórica (1291-1923) \\ 2.2.1.-De los origenes a 1890}

La institución del Somatén se remonta a la Edad Media y es originaria de Cataluña. Todos los catalanes, desde 20 a 70 años de edad, quedaban obligados a los servicios de hueste y cabalgada. El "Usatge Princeps nanque" (2) establece la obligación de acudir al llamamiento del príncipe, el cual lo haria "por letras o mensajeros o por aquel modo con que se acostumbre a avisar en la tierra".

Según don José Pella Fargas (3) esa milicia popular recibe el nombre de "somatent" y era capitaneada por delegados del monarca. Por medio del Somatén podía ser prendido cualquier malhechor aun en iglesia, monasterio o cualquier sitio inmune.

Otro proceso de "somatent" recogido por los jurisconsultos se daba en algunas comarcas de Cataluña especialmente en Gerona, cuando un presunto delito era cometido en el territorio de un señor feudal, si el preso daba el grito de "Via fora" alegando que se le había detenido injustamente, el veguer (4) tras convocar a los notables del lugar y, si se consideraba conveniente, reunia al "somatent" para ir al castillo y exigir la entrega del preso, que pasaba a la jurisdicción del Veguer.

Existia también el llamado "somatent sacramental", que resultaba de la confederación formada entre varios vecinos para su defensa. Estos procuraban el levantamiento de un número suficiente de hombres armados y dirigidos por jefes designados de antemano.

En cuanto al término "somatent", hay autores que hacen derivar la palabra de "sonsatens", estamos atentos; para otros, somatén viene de "so meten", o sea, de la forma de convocar las reuniones: "meten s'o", haciendo ruido.

Tan pronto un somatenista tenia noticia de un acto de perturbación o notaba un peligro, si por la urgencia del caso no podía avisar a un superior, daba voces y alertaba a sus vecinos e inmediatamente la campana del lugar tocaba a somatén por medio de una señal determinada. Cuando la gravedad del caso lo requería, también eran avisados los lugares vecinos mediante un tañido especial, propagándose así la llamada por medio de las campanas de los distintos lugares, de modo que al poco tiempo quedaban vigilados todos los caminos y pasos, reuniéndose en el lugar de la alarma un considerable contingente de fuerzas.

(1) Enciclopedia jurídica española. Edit. Fco. Seix Barcelona, 1910.

(2) Ley 3, tit. I, Lib. X, vol. I. Constituciones de Cataluña.

(3) "Lo Somatent, noticias históricas y juridicas de sa organisacio" 1877. Imprenta de la Renaixensa. Barcelona.

(4) Oficial público de la administración territorial que tenia funciones gubernativas, judiciales y militares. En Cataluña y Mallorca. 
La institución del Somatén aparece ya reflejada en la Constitución de Jaime II, dada en las Cortes de Barcelona de 1291. Con el mismo monarca, en 1314, se redactaron unas "Ordenaciones del Somatent", que, tras diversas vicisitudes, fueron promulgadas en 1413 por Fernando II después de su redacción definitiva. En ella se llega a un acuerdo con la Iglesia respetando la inmunidad ecleciástica. Carlos I y Felipe II también dictaron disposiciones regulando el Somatén. Durante la guerra de Sucesión, el Somatén tomó parte muy activa en defensa del pretendiente austriaco, que en 1705 instaló su corte en Barcelona. Debido a ello, Felipe $V$ en el Decreto de Nueva Planta de 16 de enero de 1716 dispuso la supresión de los somatenes "so pena de ser tratados como sediciosos los que concurrieren o intervinieren".

Sin embargo esta institución no era fácil de desarrigar en Cataluña por sus hondas raices históricas y parece ser que esta disposición quedó incumplida en la práctica. El Somatén aparece en 1794 haciendo frente a la invasión francesa y en 1808 los somatenistas de Manresa, Igualada y otros pueblos derrotaron a los franceses acaudillados por el general Schwarz.

\subsection{2. -Del Reglamento de 1890 al Golpe de Primo de Rivera}

En el año 1890 el general don Félix Camprubí redactó un reglamento para el cuerpo de somatenes armados de Cataluña. Este sirvió de base con ligeras variantes al que en 1923 aprobara Primo de Rivera. En el preámbulo, Camprubí se dirige al jefe nato del Somatén, capitán general del distrito, para que por su mediación sea presentado al Gobierno para su aprobación. Al mismo tiempo hace un recuento de los logros y méritos del Somatén desde la victoria sobre los franceses en el Bruch en 1808: la participación al lado del Gobierno de 1849 a 1855 durante la segunda guerra carlista, así como en 1875 , luchando contra las partidas acaudilladas por Ramón Cabrera, partidarias de Carlos VII. La respuesta autorizando la aprobación del Reglamento para el Cuerpo de Somatenes armados de Cataluña llegó por R. O. de 8 de junio de 1890 . Se puede observar que ya desde esta época los somatenes aparecen alineados en el campo más conservador. Su carácter mayoritariamente rural y el estar formado, en sus puestos de más responsabilidad, por propietarios principales y gentes acomodadas, contribuyen a darle este carácter. Esto se desprende del artículo cuarto del reglamento de 1890 donde se dice que el Somatén armado "es la asociación de los propietarios y colonos honrados y de responsabilidad en Cataluña, que por su amor al orden y adhesión a las autoridades han merecido de la autoridad la confianza y la autorización de guardar en su poder un arma larga y municiones para la defensa de su persona y bienes". No es de extrañar, por tanto, que el Somatén fuera disuelto ya por la primera República (273-1873) y vuelto a implantar con la Restauración de Alfonso XII.

Es significativo también que este reglamento fue redactado en un periodo conservador dentro del pacífico turno de partidos que se produjo a la muerte de Alfonso XII durante la Regencia de María Cristina. 
Especifica el reglamento que el cuerpo de somatenes armados depende del capitán general del principado, quien ejerce su jurisdicción por medio de un subinspector o comandante, que es a su vez el presidente de la comisión organizadora. A sus órdenes están los cabos y subcabos del partido judicial, los cabos y subcabos del distrito municipal, los cabos y subcabos de pueblo y todos los somatenes.

El presidente es nombrado por el Gobierno de entre los generales del Ejército a propuesta del Capitán General del Principado (art. 5).

La comisión organizadora estaba formada por dieciséis vocales, propietarios hacendados en los pueblos o caserios comprendidos dentro de la zona del Somatén y su cargo es voluntario y gratuito. La comisión cuida de todo lo relativo a la organización, disciplina y servicios del Cuerpo de Somatenes bajo la dependencia del Capitan General (art. 11). Este reglamento deja en mayor libertad a la Junta Organizadora, aún dentro de su dependencia del ejército, que el que posteriormente redactará Primo de Rivera. En este se controlará férreamente a los civiles no sólo por medio de los mandos militares, que tendrán que aprobar y sancionar hasta las más mínimas cuestiones de tipo interno, sino por la supervisión de los asesores, también vinculados al ejército.

Se extiende el reglamento a una serie de normas sobre funcionamiento interno y cuestiones de disciplina, muy estricta, observándose en esto también un espiritu castrense, con que los somatenes pueden ser castigados con multa o destitución (art. 4). También es muy celoso el reglamento en cuestiones de prestigio estableciendo que se investigue la conducta y honradez de los que pretenden entrar en la institución (art. 37) y recomendando muy especialmente a los somatenistas que vigilen y entreguen a las autoridades a aquellas personas que, sin la licencia correspondiente, usen armas o cacen "para que no puedan ser confundidos los que asi obren con los individuos del Somatén armado" (art. 36).

Establece las cuotas a pagar, en orden decreciente desde los dueños de industrias y propietarios de fincas rústicas hasta los aparceros, según las posibilidades económicas.

La edad mínima de ingreso, 23 años, se mantenía vigente en 1923 y en cuanto al armamento, según el artículo 52, corria a cargo de los somatenistas; este artículo sería modificado para Melilla como ya comentaré en el apartado correspondiente. La posesión de un arma, por los somatenistas que poseían licencia, se consideraba obligatoria, ya que eran condenados a una multa de 25 pesetas aquellos que "la enajenaran antes de sustituirla" y aquellos que cedieran su licencia de armas.

Los somatenes, según este reglamento, estaban sometidos al alcalde, como primera autoridad local, el cual tenía potestad para levantar el Somatén si lo consideraba conveniente; en este caso los cabos se les presentarian para ponerse de acuerdo en los detalles. También podían ordenar los mismos cabos el levantamiento del Somatén, en cuyo caso darían aviso al alcalde o persona que lo represente; en caso urgente podia ser reunido el Somatén y dar luego conocimiento al alcalde. Sin embargo, los alcaldes "no se opondrán a que los cabos reúnan sus fuerzas para cumplir las funciones legales del reglamento" (arts. 61 al 64).

El reglamento de 1890 deja en vigor el artículo primero de la instrucción de 31 
de marzo de 1856, que estableció que todos los varones de 14 a 60 años pertenecientes al pueblo o distrito (a excepción de los pastores) tienen obligación de asistir al Somatén con palos o instrumentos de labranza o de cualquier clase si no tienen permiso de armas. Esto ocurría en el caso de que se reuniera al Somatén general, en cuyo caso todos los hombres desarmados estarian a las inmediatas órdenes de los alcaldes.

Estos aspectos referidos a los alcaldes no los recoge el reglamento de Primo de Rivera, si bien es cierto que de manera general remite al reglamento de Cataluña. En cuanto a Melilla se da el caso de que el general segundo jefe de los somatenes, Garcia Aldave, será al mismo tiempo presidente de la Junta de Arbitrios, hasta 1927, en que fue sustituido por Manuel González Carrasco.

En cuanto a las prerrogativas del Cuerpo de Somatenes, el reglamento estipula, en su artículo 57, que aquellos somatenistas que se distingan en alguna acción meritoria, recibirán una recompensa en metálico acordada por la Comisión, además de aquellas que el gobierno pueda otorgarles. Por otra parte, los miembros del Cuerpo de Somatenes están autorizados a llevar el arma y las municiones dentro de la provincia y no pueden ser objeto de registro por parte de las autoridades, estando obligados a mostrar la licencia de armas si son requeridos para ello.

Seguin el artículo 39 nadie puede recoger a un miembro del Somatén èl arma y las municiones, salvo el capitán general, a instancias del juez, ni siquiera por faltar a la Ley de caza. El citado artículo fue derogado por R. O. de 19 de enero de 1903 especificando que "lo que no puede recogerse sin orden del Capitán General no es el arma con la que se haya cometido una fechoria sino la licencia para usar dicha arma" (5).

Los somatenes poseian también franquicia postal para la correspondencia que derivara de las necesidades del servicio, según $R$. O. de 6 de mayo de 1890 .

$\mathrm{El}$ reglamento de 1890 fue modificado o reelaborado añadiéndosele ciertas disposiciones en diversas ocasiones. En 1892 se aprobaron las "Instrucciones para el servicio del Cuerpo de somatenes armados de Cataluña". En ellas se especifica a través de los diversos capítulos cuál debe ser la actuación del Somatén en las diversas circunstancias: robos, incendios, inundaciones, huelgas. En estas se advierte que los somatenistas no intervendrán salvo si se produjeren desórdenes o tumultos que amenacen a la propiedad o a las personas (6). También se encarga a los somatenes la guarderia forestal y la vigilancia de la legalidad en caza y pesca (7).

En 1905 es proclamada patrona de los somatenes Nuestra Señora de Monserrat y con tal motivo el Rey creó una moneda conmemorativa, modelo de la que luciría la Reina madre María Cristina como protectora del patronato del Cuerpo de Somatenes. Esto da idea del prestigio y la importancia alcanzada por lo somatenes en Cataluña. Ademái, por R. O. de 1905 el Rey concede a los somatenistas el

(5) Enciclopedia juridica española. Obra citada.

(6) Cap. II, Sec. III de las Instrucciones.

(7) Cap. I, Sec. IV de las Instrucciones. 
carácter de agentes de la autoridad en aquellos actos en que presten servicio conforme a su reglamento.

El 22 de enero de 1919 el comandante general Pedro Cavanna aprueba nuevas instrucciones para el Somatén de Barcelona, organizándolo por distritos y, éstos, por demarcaciones, diferenciando, además, las zonas rurales de las urbanas (anteriormente el carácter era prioritariamente rural). Este reglamento resulta ya bastante similar al que regia en tiempos de la Dictadura de Primo de Rivera, salvo en pequeños detalles como la distribución de los somatenes en tres clases: somatenes encargados de defender las calles desde su casa, somatenes encargados de defender los puntos más convenientes del barrio y, en tercer lugar, aquellos que constituyen las rondas volantes.

\section{3.-EL SOMATEN EN MELILLA (1923-1929)}

\section{1.-Golpe de Estado de Primo de Rivera}

El 13 de septiembre de 1923 llega a Melilla un telegrama (8) procedente del Ministerio de la Guerra y dirigido al comandante general (9). En él se da cuenta de que el Capitán General de la Cuarta región Militar ha negado obediencia al gobierno, contando también con el apoyo de la Quinta Región. Se pide a continuación que las tropas de Melilla "sólo tengan su interés puesto en el honor de las armas frente al enemigo".

Efectivamente, el general Primo de Rivera, capitán general de Cataluña, en un manifiesto dirigido al pais habia pedido la destitución del Gobierno. Contaba con el apoyo de la gran burguesía catalana, debido a la gravedad que alcanzan las luchas de clase instrumentadas por las organizaciones sindicales obreras. La patronal exigía la represión de las organizaciones obreras urgentemente. Según Martínez Cuadrado (10), la invitación a Primo de Rivera, en 1922-1923, para hacerse cargo de una dictadura militar partió de los poderosos sectores que dirigían la patronal.

En Melilla, la población estaba muy sensibilizada con los problemas del Rif. Desde el año 1919 la guerra en las montañas del este, muy próxima a los enclaves de Melilla, preocupaba profundamente a la población. Los rebeldes dirigidos por $\mathrm{Ab}$-del Krim infligieron importantes derrotas al ejército que cometió grandes errores tácticos y administrativos que desembocaron en los desastres de Annual, Monte Arruit, etc. Estos sucesos acabaron de formar en la península una corriente antimilitarista, y grandes sectores de la población española eran contrarios a invertir más dinero y vidas en Africa. El mismo ejército quedó escindido en esta cuestión entre africanistas y renovadores.

(8) Documento $\mathrm{N}^{\circ} 1$ del Anexo.

(9) MARZO BALAGUER. Desde el 21 de agosto de 1923.

(10) MARTINEZ CUADRADO, Miguel: "La burguesia conservadora." Alfaguara. Madrid, 1981. 
La Dictadura de Primo de Rivera con su promesa de solucionar el problema de Africa fue por tanto bien acogida en Melilla, donde se deseaba un Gobierno fuerte. No obstante, en la respuesta, al telegrama del Ministro de la Guerra anunciando el golpe de estado, el Comandante General de Melilla se declara fiel al gobierno constituido y a las instituciones. Sin embargo, el 14 de septiembre se recibe otra comunicación advirtiendo que el presidente ha presentado la dimisión. El motivo, según especifica el telegrama, es que habiendo sido presentada al Rey una propuesta para solucionar la situación, éste ha diferido la respuesta, dimitiendo entonces el presidente y el Gobierno en pleno.

Uno de los primeros actos de Primo de Rivera como presidente del Directorio militar fue la extensión del Somatén de Cataluña a todas las regiones españolas. Sin duda, durante su estancia como capitán general en Cataluña, advirtió valores en esta institución, que le indujeron a pensar que sería un valioso apoyo al régimen. Así, en el manifiesto de 15 de septiembre de 1923 (11). Primo de Rivera anuncia que el decreto de organización del "Gran Somatén Español" tardará solo horas en salir.

En este manifiesto se observan las líneas generales de lo que se espera de esta institución. Habla Primo de Rivera del lema del Somatén "paz, paz y siempre paz", asegurando que esta paz la quiere fundada "en el saludable rigor y justo castigo". Propone un Somatén reserva y hermano del ejército pero pone un énfasis especial en asegurar: "lo queremos más para organizar y encuadrar a los hombres de bien y que su adhesión nos fortalezca."

El R. D. instituyendo el Somatén en toda España (12) fue dictado el 17 de septiembre de 1923 y publicado el día 18 en la "Gaceta de Madrid". En la exposición de motivos, enviada al Rey acompañando al Real Decreto, distingue el Marqués de Estella unos de orden práctico, como la garantía del orden público y otros de orden moral "por lo que estimulan el interés ciudadano hacia una orientación activa y desinteresada".

El Somatén es organizado por regiones militares siendo comandante general un general de brigada de infantería en la capital de la región y jefes natos, los capitanes generales respectivos (art. 3). Hay, pues, a pesar de tratarse de una organización civil, una absoluta dependencia del ejército.

Una prueba de la importancia que concede Primo de Rivera a los somatenes es su premura por organizarlos. En el artículo séptimo se da el plazo de un mes a los capitanes generales para la organización del Somatén en sus respectivas regiones, debiendo, al final de este plazo dar cuenta al Ministerio de la guerra de su realización.

\section{2.-Posibles conrotaciones fascistas en el Somatén}

Diversos autores se han ocupado en estudiar hasta qué punto intervino el ele-

(11) Publicado por El Telegrama del Rif, 16 de septiembre de 1923.

(12) Documento N. ${ }^{\circ} 2$ del Anexo. 
mento fascista en la Dictura de Primo de Rivera; es casi unánime la convicción de que no hubo un fascismo de corte italiano ni siquiera en las motivaciones que llevaron al general al golpe de Estado. Para Jordi Cassasas existió un intento de remodelación del bloque dominante y al mismo tiempo un intento de recambio de la clase politica de acuerdo con aquella remodelación. Para esto era necesario construir una ideología, unas motivaciones que sustentaran el edificio del régimen. En todo este aparato externo es evidente que existen afinidades con Italia desde los inicios de la Dictadura, como el ensalzamiento del jefe o caudillo, las manifestaciones multitudinarias de adhesión hábilmente dirigidas o el recurrir a plebiscitos. Se exalta el valor, la masculinidad unida al ejercicio de las virtudes castrenses, el sacrificio por la patria, etc. Existe también un decidido empeño desde el poder en frenar la revolución social y el comunismo como peligros mundiales.

Las referencias italianas pueden verse claramente en la reorganización, ya desde los primeros dias de la Dictadura, del Somatén, a modo de cuadrillas o fascios, como elementos de apoyo al Régimen y al que se constituiria en partido único a partir de 1924, la Unión Patriótica. El Corriere de la Sera del día 19 de marzo de 1929 (13) publica un entrevista de su corresponsal Pablo Minelli con Primo de Rivera. En ella el entrevistado hace referencias expresas al Somatén como fascio al estilo italiano.

Dice textualmente Primo de Rivera: “...lo que sí puede parecerse más a un fascio son los somatenes, que no son más que una unión de gente honesta y armada para la defensa y el orden, pero no suman en España más de ciento veinte mil." Lo cierto es que el Somatén no tuvo en España la agresividad ni la radicalización activa del fascio italiano. A pregunta del periodista italiano, el general manifiesta su confianza en el Somatén diciendo que no cree ni remotamente que esta fuerza armada pueda ponerse en contra del gobierno ni representar un peligro, esto sería desde luego impensable puesto que a la hora de la aceptación de los miembros del cuerpo se actuaba con un criterio muy estricto, si nos atenemos a lo que estipula el reglamento.

A lo largo de la entrevista Primo de Rivera minimiza las algaradas estudiantiles y los problemas graves a los que ya se enfrenta el régimen en el año 1929 y hace grandes elogios de Mussolini, hacia el cual sentia una gran admiración, pero hace notar las diferencias de su régimen con el italiano. Afirma que mientras Mussolini ha creado un nuevo Estado con unas instituciones nuevas, en España la dictadura no ha cambiado nada en sus fundamentos, "lo que cambia son los métodos y los hombres, había más orden, más honestidad, más deseo de trabajar y un mejor desarrollo económico y financiero". Sin embargo, en un principio, se buscaba una identificación con el sistema italiano, prueba de ello son los viajes a Italia de Alfonso XIII, Primo de Rivera o Aunós; para Jordi Cassasas estos viajes tenían como objeto la inspiración para ulterior ensayos además de la búsqueda de una

(13) 'El Telegrama del Rif, número 10.338 del 27-3-29 (facilitada, según especifica, por el negociado de censura). 
identificación. Para Ortega y Gasset (14) el entusiasmo que provocaban estos viajes procedia de que se creía encontrar en Italia un movimiento análogo en el fascismo, sin embargo, el Duce, en un discurso, estableció muy cortesmente las diferencias esenciales entre ambos movimientos. Sigue diciendo Ortega que el golpe de Estado de Primo de Rivera no es más que "un pronunciamiento" idéntico en su génesis $y$ en su mecanismo a los del pasado siglo, aunque en sus consecuencias haya provocado las reacciones peculiares del instante". Cambó va aún más lejos y afirma que no existen entre ambos fenómenos más que una coincidencia cronológica. Pero lo que si es un hecho, es que existieron unas afinidades ideológicas y una corriente de mutua simpatia al menos en los primeros tiempos. En su discurso durante su viaje a Italia, Primo de Rivera pronunció unas palabras muy significativas: "Permitidme que al dirigiros a vos y a Italia un saludo, como presidente del Directorio que soy y en nombre del pueblo español, enaltezca, como jefe que soy de los somatenes, y en nombre de éstos, al fascismo."

\section{3.-Organización del Somatén en Melilla (1923-1924)}

En cumplimiento del R. D. de 17 de septiembre de 1923 ordenando la organización del Somatén en toda España, se ponen en marcha también en Melilla los mecanismos para dar forma a este orden del nuevo Gobierno. Asi el 26 de septiembre el comandante general designó al general segundo jefe, Garcia Aldave, para que procediera a la organización del Somatén de Melilla y el 7 de noviembre ya existia un reglamento provisional.

Este reglamento dividía al Somatén en las diez secciones o barrios siguientes: Alcazaba, Mantelete, Pueblo, Polígono, Bateria J, Príncipe de Asturias, Reina Victoria, Obrero, Industrial, Hipódromo, Real, Carmen y Tesorillo. Se estipula que al frente de cada una de estas secciones habrá un cabo y varios subcabos y vocales. También se anuncia que se designará un jefe u oficial retirado del ejército para la instrucción de los somatenistas. Tres días más tarde se pidió el concurso del teniente coronel retirado de la Guardia Civil, don Pedro Nogueira, en ese momento jefe de Policía, para la organización del Somatén.

Desde la Junta de Arbitrios, presidida por el general Garcia Aldave, se realizaron todas las gestiones destinadas a llevar a cabo la organización del Cuerpo de Somatenes local. En cuanto a este reglamento provisional, fue enviado por la Comandancia General a la Junta de Arbitrios, que, el mismo día, 7 de noviembre convocó una reunión de sus miembros para ultimar los detalles. A esta reunión asistieron representantes de distintas corporaciones, entidades y centros a través de las cuales puede decirse que estaba representada la flor y nata de la sociedad meli-

(14) España encadenada. La verdad sobre la dictadura. Paris, 1925. Cap. XVIII. Citado en Jordi Cassasas Imbert. "La dictadura de Primo de Rivera, 1923-1930. Textos." Authoropos. Barcelona, 1983. 
llense de la época. Estuvieron presentes miembros de las Cámaras Oficiales de Comercio, Agricola y de la Propiedad; Compañia Transmediterránea; Compañia Española de Minas del Rif; Casino Español; Circulo Mercantil; Bancos de España, Bilbao y Cartagena; Tiro Nacional; Compañia Setolazar; Compañia Norteafricana; Unión General Mercantil; Compañia Hispano Marroqui de Gas y Electricidad y los periódicos La Gaceta de Melilla, El Popular, El Noticiero del Rif y El Telegrama del Rif.

No es extraño este interés por intervenir en la marcha de la organización del Somatén si se tiene en cuenta que se pensaba que podria ser un excelente instrumento para quien lograra hacerse con el control de esta institución, mediante la colocación de sus amigos o allegados en los puestos de mando.

\subsection{1.-Disensiones internas en torno a la organización del Somatén}

La reunión del día 7 de noviembre en la Junta de Arbitrios resultó por tanto muy movida y es recogida ampliamente en la prensa local. Esta reunión fue convocada con el objeto de contar con el apoyo de las personas más significativas de la vida local de forma que constribuyeran al sostenimiento del Somatén en Melilla. Así lo manifestó el general García Aldave que presidia la reunión; sin embargo, estas personas no prestaron un apoyo incondicional sino que exigieron datos y nombres antes de decidir. Este es el caso de Jaime Tur (15) o el del presidente de la Cámara Agrícola, señor Cuevas. Otros representantes de entidades locales expresaron la necesidad de convocar el pleno de las mismas antes de tomar una decisión.

La lectura de los nombres de las personas designadas como jefes de sección de los somatenes fue acogida, según cita textualmente El Telegrama del Rif, del 8 de noviembre "con un silencio profundo, significativo y embarazoso". Entre los designados, una mayoria abrumadora pertenecia a personas de manifiesta significación política y social: un comerciante acaudelado, un consignatario de buques, un agente de la Compañia Transatlántica, un procurador, un catedrático, el secretario de la Junta de Arbitrios, etc.

El presidente de la Cámara Agrícola, señor Cuevas, fue quien más destacadamente intervino oponiéndose a los nombramientos y expresando, según el citado periódico, la opinión general: "el temor de que bien a pesar del celo de las autoridades, se convirtiesen (los somatenes) en un instrumento de caciquismo." Siguió diciendo el señor Cuevas que dichos nombramientos debian recaer "en personas alejadas de las luchas locales, que no hubiesen sido objeto de críticas ni censuras más o menos justificadas y que tuvieran su domicilio en el distrito del que iban a ser jefes". Pidió además que "aquellas que han de mandar ciudadanos en armas tengan garantías de ecuanimidad, independencia, rectitud y valor". Recordó, después, a

(15) Periodista. Seria Secretario de la Junta Centrả del Somatén y abanderado. 
los alli reunidos, los trágicos sucesos de 1921 , cuando hubo personas para quien fue más fuerte "su sentido de conservación que el sentido del deber". Seria doloroso, dijo, que esto pudiera repetirse. Las durisimas palabras de Cuevas hacen pensar que tenia el respaldo de una mayoría que pensaba como él. Lo que si puede asegurarse es que tenia el respaldo del periódico, que da cuenta de esta reunión, puesto que su director, Cándido Lobera (16), publica un editorial (17) advirtiendo del peligro que supondria que el Somatén fuera manipulado en provecho de intereses particulares. Opina Cándido Lobera que muchas de las instituciones y organismos del anterior régimen dieron pésimos resultados, no por las leyes que la inspiraron, "sino por la estulticia, la inmoralidad y la incultura de las personas llamadas a ejecutarlas" y pone como ejemplo la ley del Jurado, derogada por el Régimen de Primo de Rivera. Esta ley manipulada en la práctica por los caciques había dado pésimos resultados. En cuanto al Somatén, piensa que si no es dirigido por los hombres adecuados, es decir "por personas que, además de su reconocida solvencia moral, no se signifiquen en ningún sector de la vida política y social de la ciudad", puede convertirse en "máquinas del caciquismo y hacer más fuerte su obra negativa y destructora".

No es extraña esta prevención contra el poder del caciquismo, que desce hacia largos años constituía un entramado que manejaba los hilos de la vida política y social en España. Los caciques ejercian un control total sobre las elecciones manejando a los votantes a su antojo. El sistema canovista y el turno de partidos durante la Restauración fueron prueba de ello. Por medio del caciquismo se pudo implantar el sufragio universal en 1890 sin que las oligarquías perdieran los resortes que controlaban el resultado de las elecciones. Normalmente esto ocurria sin violencia, pues los votantes seguian sin más al cacique rural pero si era necesario se llegaba a la fuerza 0 al encarcelamiento. ¿Cómo no temer que una naciente fuerza armada y civil cayera en manos del caciquismo? Sin embargo, eran innecesarias tantas precauciones puesto que la inmovilidad política durante la dictadura de Primo de Rivera acabó con él; quiso volver a imponerse pero el fracaso del sistema caciquil se demostró en las elecciones de abril de 1931.

Las protestas sobre la organización del Somatén dieron su fruto y el general presidente optó por dar cuenta al comandante general de lo sucedido y anular los nombramientos. Sin embargo, el día 11 de noviembre, tres dias después del editorial de Cándido Lobera, los directores de todos los periódicos locales fueron llamados al despacho del comandante general para tratar el asunto del Somatén. De lo ocurrido en la reunión nada se sabe pero desde entonces sólo aparecen en la prensa noticias escuetas o encendidas alabanzas para el Somaten. El 3 de abril de 1924 una comisión de los principales comerciantes de la ciudad visitó la redacción del Telegrama del Rif para informarse sobre la organización del Somaten y conocer el

(16) Presidente de la Junta Municipal, 1928-1931. Somatén primer dto.

(17) Telegrama del Rif. 8-11-23. ("Nuestra opinión.") 
ambiente local respecto a la misma, extrañados del silencio de la prensa. El periódico le recomienda que visite al señor Nogueira y justifica su silencio, que es debido a "deberes ineludibles de acatamiento a la censura".

Desde las disensiones de noviembre de 1923 pasaron seis meses hasta la salida de los nuevos nombramientos; esto ya era indicio del escaso eco que tuvo en la vida local la institución del Somatén, controlada férreamente por el ejército y con escasa participación de personas significativas. No pareció despertar demasiado interés entre la población.

El día 9 de mayo de 1924 el Telegrama del Rif publica los nombres de los miembros de la Junta Central y de los cabos de los diez distritos:

Presidente, General Garcia Aldave.

Vicepresidente, Pedro Nogueira, Tte Coronel de la Guardia Civil retirado. Secretario, Jaime Tur (periodista).

Tesorero, Antonio Paredes.

Cabos:

Distrito 1. Antonio Bernadi Tebas (agente de transporte).

Distrito 2. Ramiro Santamaria (ultramarinos).

Distrito 3. Francisco Romero (comandante retirado).

Distrito 4. Félix Sánz y Sánz (comerciante).

Distrito 5. José Barrientos (médico).

Distrito 6. Francisco Sempere (director escuela indigena).

Distrito 7. Juan José Mons Climent (profesor 1. a enseñanza).

Distrito 8. Guillermo de Arce (propietario).

Distrito 9. José Fernández Hita (constructor de carros).

Distrito 10. Francisco Murias Rodríguez (contratista).

\subsection{2.-Reglamento para el Somatén de Melilla}

Se aprobó el 4 de noviembre de 1923 y fue publicado el día 8, firmado por el teniente coronel José Sánchez de Ocaña. Según el reglamento, el Somatén de Melilla constaba de tres grupos: Somatén de la ciudad, Somatén de los cotos mineros y Somatén de los poblados (18). Ninguno de estos grupos podía intervenir fuera de su demarcación, salvo en casos especiales, como podía ser en estado de guerra. El Somatén de la ciudad tenía un carácter urbano mientras que los otros dos eran de carácter eminentemente rural. Estos tres grupos tenían un solo presidente, que por el artículo 8 del reglamento había de ser un general de brigada y se denominaria Comandante General de los Somatenes de Melilla y su territorio. Sería, al mismo tiempo, el presidente de la Junta Central compuesta por un vicepresidente, 16 vocales, que serán los jefes de distrito, un tesorero y un secretario.

Cada uno de los 16 barrios de la ciudad tenía un somatén con una junta com-

(18) Nador, Zeluán, Monte Arruit y Zoco Arbaá de Ar Keman. 
puesta por un jefe, tres vocales y un asesor militar escogido entre los jefes y oficiales del ejército, retirados (art. 4). Este asesor no tenia derecho a ventajas militares ni mejoras (art. 13), era el encargado de asesorar al jefe de los somatenes en caso de conflicto, también estaba obligado a pasar revista al armamento y municiones.

La Junta Central se reunia, según estipula el reglamento, "cuando el comandante general del territorio lo disponga", si bien reglamentariamente debia reunirse cada dos meses. Esta Junta Cental estaba bajo la total supervisión del Comandante General, que tenía que sancionar todos sus acuerdos para que fueran válidos. Dependientes de la Junta Central, las juntas de barrio se reunian para tratar previamente las altas y bajas, también se encargaban de recibir del asesor el parte de revista del armamento y pasarlo a la Junta Central. Asimismo, se estipulaba que estas juntas de barrio tuvieran una lista en la que constara el nombre, domicilio, profesión, edad y conducta de los afiliados (art. 25). En caso de estimarlo conveniente podian proponer una sanción, que podia llegar a significar la baja en el cuerpo, sin embargo, debian ponerlo en conocimiento de la Junta Central. Cuando se tratase de vocales, jefes de barrio y miembros de la Junta Central, tanto las bajas como los nombramientos eran de la exclusiva competencia del Comandante General.

En el artículo segundo del reglamento se especifican las obligaciones del Somatén: "El Somatén de la ciudad tiene por objeto: defender la ciudad y la vida y hacienda de sus habitantes, hacer respetar las leyes y a las autoridades; garantizar el funcionamiento de los servicios públicos y mantener el orden dentro del término de soberania." Lo anterior es complementado por los artículos 25 al 28: el Somatén como fuerza armada no puede ser empleado más que en casos extremos y siempre dentro de la población; también se establece que en caso de huelga $o$ alteraciones del orden que paralicen los servicios públicos deben presentarse inmediatamente a sus superiores. Por otra parte se habla de que en caso de guerra estarán sujetos al Código de Justicia Militar. Como se ve se trataba de tener una milicia de reserva, además de una fuerza ciudadana, aunque de hecho no se utilizó en uno ni otro aspecto, entre otras cosas porque concretamente en Melilla no interesó especialmente a la población, hasta el punto que fue necesaria una modificación al reglamento general de somatenistas. En el artículo octavo se estipula que los somatenistas deben usar armas largas de su propiedad con dotaciones de 25 cartuchos. Sin embargo, en vista de la escasez de personas alistadas al Somatén de Melilla, el general en jefe del ejército de operaciones en Marruecos dirigió un escrito al Directorio Militar atribuyéndolo a que "la mayoría de habitantes carece de recursos para adquirir el armamento"y las municiones" (19). Atendiendo a este escrito el ministro de la Guerra publicó una Real Orden, fechada el 3 de junio de 1924, en la que dice que "teniendo en cuenta las especiales circunstancias de nuestras plazas de soberania en Africa... el Rey se ha dignado disponer que a los individuos de las pla-

(19) Publicado en El Telegrama del Rif el 1 de junio de 1924. 
zas de Africa pertenecientes al Somatén y que carezcan de recursos para adquirir armamentos y municiones reglamentarias se les facilite en la forma y mediante las condiciones siguientes".

Las especiales circunstancias a que se refiere la $\mathbf{R}$. 0 ., es decir,la guerra de Africa con los continuos incidentes con los rebeldes de Abd-el-Krim, movieron al Directorio a dotar a los somatenistas con el suficiente armamento y munición como para constituir una posible defensa de la población y sobre todo para que fuera posible darle vida a esta institución en las plazas de soberanía. Así se dotó gratuitamente a los somatenistas de Melilla de fusil Mausser con bayoneta y 100 cartuchos de guerra. Este armamento lo recibian en calidad de depósito necesitándose, para extraerlo, orden expresa del comandante general de la zona a propuesta del comandante general de los somatenes. Obligando a los somatenistas a cuidar debidamente el armamento para lo que se le facilitarian piezas de recambio, también a no ausentarse con el armamento de la zona a la que pertenece, debiendo entregarlo si su ausencia va a ser definitiva y exigiéndosele responsabilidades por su pérdida o deterioro.

\section{4.-Evolución del Somatén y significación social y política (1924-1929)}

El 21 de junio de 1924, con los nombramientos de los asesores militares de los diez distritos, puede decirse que se pone por fin en marcha el Somatén de Melilla. Estos asesores fueron nombrados por el entonces comandante general Sanjurjo, a propuesta de García Aldave, y todos ellos, a excepción del teniente de ingenieros Gregorio Pérez Peinado, eran oficiales retirados del ejército. Desde luego el Somatén de Melilla no se distinguió por la juventud de sus miembros sino que estaba compuesto en su mayoria por hombres de edad madura.

En cuanto al número de afiliados, no fue nunca demasiado elevado, en junio de 1924 ascendía a 558, de los cuales el grupo más nutrido, 100, correspondía al segundo distrito, barrio de Reina Victoria, es decir el centro de la ciudad. En este distrito estaban por tanto las personas más conocidas y que podía considerarse de tendencias más conservadoras. El distrito cuarto, que abarcaba los barrios del Carmen, el Ensanche y el Polígono alto era el que menos somatenistas aportaba 33 .

Para darle auge al Somatén de Melilla se intentó no solo una medida de orden práctico, como la ya citada del armamento gratuito, sino otra de orden psicológico, como abrir una suscripción popular, a la que sólo podían concurrir las mujeres, con objeto de regalar una bandera a los Somatenes armados de Melilla. La prensa refleja día a día las cantidades aportadas y los nombres de las donantes; todo esto lleva implicito una exaltación del Somatén, con métodos de propaganda parecidos a los que, en tiempos de lucha, se establecen relacionando la mujer y las fuerzas armadas. El día 25 de octubre de 1924 fue entregada la bandera, confeccionada y pintada por las profesoras y alumnas de la escuela de dibujo de Melilla. Se dio a la ceremonia gran brillantez declarándose el día festivo y celebrándose el acto en la Plaza de España. 
La madrina, Belén Garcia Aldave, exaltó en su discurso el valor de los somatenes como lazo de unión entre la población civil y la militar, al constituir una milicia ciudadana. Los somatenes, aún dentro de una estricta disciplina, no fueron nunca uniformados, sino que usaban únicamente un distintivo como modo de identificación, aparte del carné de somatenista. Se aprecia en esto que se intentó que no perdieran nunca su carácter civil, sino por el contrario que sirvieran de introductores, dentro de la población civil, de los valores castrenses y al mismo tiempo de puente entre el pueblo y el ejército, cosa muy comprensible dado el régimen militar del momento; por otra parte, esto, en Melilla, no era muy dificil de conseguir dado el carácter eminentemente militar de la Plaza.

Es de destacar, también, tanto en el discurso de la madrina como del propio general García Aldave, la certeza absoluta de que no seria necesaria la utilización del Somatén. Se exalta de este modo el orden público conseguido con el régimen de Primo de Rivera, que hace innecesarias instituciones de este tipo. Garcia Aldave y la madrina hacen alusiones al lema de los Somatenes, "Paz, paz y siempre paz", pero afirmando que "la patria puede contar con una organización de reserva que velará por su honor, si críticos momentos lo exigieran, circunstancias en las que no puede pensarse existiendo, como existe, para garantía de la ciudad de melilla el nombre heróico del general Sanjurjo". Hay, pues, una total exaltación del régimen y del ejército en este acto tan brillantemente orquestado en el que no faltaron los niños con banderitas, el desfile a los sones de la Marcha Real ni la novedad de la escuadrilla de hidroaviones sobrevolando la Plaza de España.

Los elementos indigenas estuvieron representados por el Naib Sidi Dris Riffi y el Kaid de Guelaya, Abd-El-Kader. Es de notar la política de acercamiento a los kabileños amigos, cuando ya se prepara la campaña de pacificación de Marruecos.

En este acto de entrega de la bandera, el número de somatenistas habia ascendido a 1.200 , número no demasidado elevado si se tiene en cuenta que la población de Melilla en la década de los 20 ascendía a 50.000 habitantes (20), pero es indudable que habían aumentado en número considerable desde junio; a ello contribuyó en gran medida la visita a Melilla de Primo de Rivera, realizada el 18 de julio de 1924. El Telegrama del Rif recoge con grandes titulares el enorme éxito del Somatén en el acto del recibimiento y las encendidas palabras de elogio del presidente del Directorio, comentando también que "todas las clases sociales tienen nutrida representación" (en el Somatén) y destacando que "no figura el corro de amigos que tal vez soñaran utilizarlo como instrumento en la politica local". De este modo se intenta presentar al Somatén como una institución ciudadana aséptica y alejada de todo partidismo.

El número de somatenistas que desfilaron ante Primo de Rivera estaba en torno a los 800 , que más tarde llegarían a los 1.200 citados anteriormente; sin embargo, lo más significativo, aparte de su escasa representación cuantitativa, es

(20) A partir de 1925 se acusa un aumento demográfico consecuencia de la pacificación del territorio. 
también lo poco destacable de su actuación, ya que no se constata a través de la prensa ningún hecho importante salvo la colaboración en sucesos de muy poca importancia; esto no parece que fuera asi sólo en Melilla, sino que en todo el pais no pareció tener mayor significado, fue más bien una organización utilizada como adorno del régimen pero a la que nunca se pensó en dar la suficiente autonomia para que fuera verdaderamente efectiva.

En una circular que Primo de Rivera envió a los somatenistas el 25 de abril de 1926 (21) con motivo del día de Nuestra Señora de Monserrat, Patrona de los Somatenes, habla de la escasa actuación de esta organización: "por fortuna la situación del pais no ha exigido la actuación de los Somatenes más que en contados casos y aisladamente... Si algún día fuera justificada la actuación colectiva contra desbordamientos sociales, el Somatén cumpliría su deber." Califica el marqués de Estella a la institución como una reserva para la garantia del orden y afirma, también, que el Somatén no representa ningún partidismo político. Sin embargo, es evidente que representaba a la clase que en ese momento ostentaba el poder, que tuvo como una de sus metas principales el mantenimiento del orden público, si bien intermitentemente habían creado problemas al régimen, los regionalistas, las Juntas de Defensa, los intelectuales y, ya en el año 1929, fueron frecuentes las algaradas estudiantiles, los problemas surgidos con el arma de artillería y con la patronal, como consecuencia de la crisis económica y de los problemas con la Organización Corporativa del Trabajo. El Somatén siempre se mantuvo fiel al régimen contribuyendo con manifestaciones de adhesión en los momentos problemáticos; prueba de ello es el documento adjunto, de septiembre de 1928, en el cual se cita a los somatenistas para un acto de adhesión al marqués de Estella al que se califica de "salvador de la Patria".

El 19 de abril de 1929 El Telegrama del Rif reproduce la Real Orden, número 10.356 , creando "un registro de personas propicias a la difamación", que debían tener los somatenistas bajo su custodia personal para "el eficaz cumplimiento de las medidas destinadas a establecer el orden público y hacer que la actuación de los Somatenes se desenvuelva con los mejores resultados". Según la R. O., los somatenistas reunirian los datos y antecedentes de las personas que hablaran contra el régimen, que comunicarían a los auxiliares militares, quienes remitirian copias a la Comandancia General. Esto es ya una prueba evidente del descontrol de un régimen que se tambalea e intenta utilizar a los Somatenes como fuerza totalmente adicta.

\section{4.-Disolución del Somatén (1931)}

Debido a su matiz conservador no le pareció oportuno a la Segunda República mantener la institución del Somatén, siendo disuelto por decreto de Alcalá Zamora

(21) Documento N. 3 del Anexo. 
el 15 de abril de 1931. Este decreto apareció junto con otro derogando el código de la Dictadura.

El jueves 23 de abril aparece un anuncio en El Telegrama del Rif comunicando a los somatenistas que aún no hayan entregado el armamento, municiones y divisas, que lo entreguen en la disuelta comandancia de Somatenes, situada en la calle General Marina, 25.

Pese a ello, en Melilla se intentó gestionar la continuidad del Somatén sobre todo en los poblados, por medidas de seguridad. Echeguren, miembro del comité local de la conjunción republicano-socialista se desplazó a Madrid para gestionar, entre otros asuntos, el concerniente al Somatén. Alegó Echeguren que el carácter del Somatén de Melilla era distinto totalmente al de la Península, por su circunstancia fronteriza, de la que podian surgir problemas, como los trágicos de 1921, y que, especialmente los vecinos de Nador, Zeluán, Monte Arruit y todos aquellos destinados a la colonización, tenían necesidad de un arma como defensa.

Propuso que se hiciera una excepción con Melilla permitiendo el Somatén, si bien reorganizándolo con personas adictas al nuevo régimen. Se pretendió, pues, una institución gemela, pero al servicio de la República. Esta proposición no llegó a buen término y los somatenes permanecieron disueltos hasta enero de 1936 en que fue autorizada su organización en Cataluña. El 9 de octubre de 1945 (Ministerio de la Gobernación B. O. 25) el general Franco decretó la Formación de somatenes en todo el término nacional, dependientes del Ministerio de la Gobernación.

\section{5.-Anexo documental}

\section{1.-Documento N. $^{\circ} 1$}

Ministro guerra a comandante general en 13 septiembre 1923. (Urgente). - La cuarta región con su capitán general a la cabeza ha negado obediencia al Gobierno y obtenido solidaridad con la quinta región. Manifiesto lanzado por general Primo de Rivera al país pide destitución Gobierno. Las más guarniciones acusan tranquilidad. Espero que las tropas a las órdenes de V. E. sólo tenga su interés puesto en el honor de las armas frente al enemigo.

Comandante general a ministro guerra en 13 septiembre de 1923.-Acuso recibo telegrama V. E. sobre sucesos cuarta región y conforme he manifestado a alto comisario para que los transmita al Gobierno este ejército que está frente al enemigo se mantendrá unánimemente atento a su misión de defender el honor de España y fieles al Gobierno constituido y a las instituciones dentro de la más severa disciplina que sabré mantener. 
Ministro guerra a comandante general en fecha 14 septiembre de 1923.- Presidente del consejo ha propuesto a S. M. las medidas que creyó conveniente solucionar situación y habiendo diferido el rey la propuesta pues necesitaba tiempo para reflexionar el presidente ha presentado la dimisión de todo el Gobierno. Lo digo a V. E. para su conocimiento y el de sus subordinados.

\section{2.-Documento $N^{\circ} 2$}

R. D. instituyendo el Somatén. 17 septiembre de 1923

Señor: En el Instituto de Somatenes de Cataluña, organismo de rancio y glorioso abolengo español, se reúnen todos aquellos hombres de buena voluntad, amantes del orden y celosos de sus deberes ciudadanos.

La recia estirpe de esta organización cívica y la briosa historia de sus hechos, en la paz y en la guerra, ha creado en los Somatenes catalanes aquella honrada solidaridad y aquel vigor espiritual tan necesitados en las colectividades cuyo fin primordial es la conservación de la paz pública.

En todas las regiones españolas podrían contar las autoridades con un tan poderoso auxilio si en las provincias que las constituyen se crease el Somatén, organización que no sólo se ciñe a dar fuerza y vigor al espíritu ciudadano, sino que separando los ánimos de pasividad e indiferencia, los moviliza en el significado de la insustituible palabra "som-atent: estamos atentos".

Por estas consideraciones, más de carácter práctico, en cuanto se concretan las garantías del sosiego público, y otras de orden moral, por lo que estimulan el interés ciudadano hacia una orientación activa y desinteresada, el Presidente que sus cribe tiene el honor de proponer a V. M. el siguiente proyecto de Real Decreto: [...].

Artículo $10^{\circ}$-Se instituye el Somatén en todas la provincias españolas y en las ciudades de soberanía del territorio en Marruecos.

Artículo 2. - -Se podrán alistar en él todos los individuos mayores de 23 años que tengan reconocida moralidad y ejerzan profesión en las localidades en que residen.

Artículo $3 .^{\circ}$ - Se organizarán por Regiones militares, siendo Comandante general un general con mando de brigada de Infantería en la capital de la Región, y Jefes natos los Capitanes generales respectivos.

Artículo $4 .^{\circ}$ - Se aplicará la organización del Somatén de Cataluña, y en cuanto se refiere a Jefes y Oficiales del Ejército, auxiliares por ahora, serán elegidos por cada Capitán general entre los que se hallen destinados en las demarcaciones de Reserva y Caja de Recluta, sin devengar por ello aumento de sueldo ni gratificac i ón.

Artículo $50^{\circ}$ - Usarán armas largas de su propiedad, cuyo entretenimiento corresponde a los que las usan, y las autoridades militares concederán a los cabos, subcabos y escoltas de bandera el uso de armas cortas en todo el territorio de la Región. 
Artículo $60^{\circ}$ - Los individuos del Somatén serán considerados como fuerza armada cuando se declare el estado de guerra y así lo consignen los Capitanes generales en sus bandos, y como Agentes de la Autoridad siempre que, no estando declarado el estado de guerra, sean requeridos sus servicios por las autoridades; se exceptúan los casos de persecución o captura de malhechores, en cuya circunstancia obrarán como tales agentes sin previo requerimiento de auxilio.

Artículo $7 .^{\circ}$ - Los Capitanes generales procederán inmediatamente de la publicación de este Decreto a organizar los Somatenes de sus respectivas Regiones, y en el plazo de un mes darán cuenta al Ministerio de la Guerra de hallarse organizado.

Artículo 8. - - Los respectivos reglamentos que se redactan serản autorizados, provisionalmente, por los Capitanes Generales de las Regiones y remitidos después al Ministerio de la Guerra para su aprobación definitiva.

("Gaceta de Madrid", 18 septiembre 1923)

\section{3.-Documento $N^{\circ} 3$}

\section{SOMATENES: Paz y Salud}

El próximo día 27, consagrado por la Iglesia a la Virgen de Monserrat, Patrona del Gran Somatén Español, nos da adecuada ocasión a todos los que lo formamos; no sólo para acendrar nuestra devoción a la excelsa Patrona, sino para fortalecer y afirmar nuestros propósitos de seguir prestando en el Somatén los servicios patrióticos que él demanda y para que fue creado.

Hemos llegado con robustez a la mayoría de edad, venciendo las resistencias que el apocamiento ofrece a lo nuevo, a lo que singulariza y las que creó la insidia o la ironia, demostrando los que la despreciaron, la fortaleza de sus convicciones, haciéndose con ello dignos del título de ciudadanos.

Por fortuna, la situación del país no ha exigido la actuación de los Somatenes más que en contados casos y aisladamente; pero en ellos ha demostrado la Institución su buen espíritu y la clara comprensión de sus deberes. Si lo que no es de esperar, mientras los resortes de Gobierno no se debiliten en España, algún día fuera justificada la actuación colectiva contra desbordamientos sociales, el Somatén cumpliria su deber.

En las sociedades modernas, las pasiones exacerbadas por las predicaciones extremistas, crean es ados latentes de pugna que lamentablemente algunas veces degeneran en luchas. Los que reclaman su derecho a propalar sus ideas y a organizar su actuación, no pueden desconocer el reciproco de defender el ideario que otros creen bueno para la existencia fuerte de la Patria. Y en esta controversia, que no debiera pasar nunca del terreno doctrinal, aunque algunas veces lo rebase, el Estado no puede ser neutro ni amorfo, sino que ha de favorecer lo que, según el espíritu de sus leyes, es esencia de su vida. No obstante, el Somatén no representa 
un partidismo politico ni de clase, sino un campo propio y común para todos los que aspiran a que la vida ciudadana se desenvuelva en un ambiente de orden, respeto a la autoridad y a la propiedad, libre de imposiciones y violencias, fácil al progreso razonado y evolutivo que el estudio y la experiencia aconsejen para el bien de todos, anteponiendo siempre el de los humildes, que lo necesitan más, y que practicamente lo lograrán más pronto y mejor reinando la paz, que en los estados de turbulencia. El orden, es siempre garantía de libertad y progreso.

Por grande que sea mi satisfacción al contrastar el floreciente estado del Somatén, mi felicitación por ser personal es modesta, pero muy sincera y esperanzada en que cada día sean más y más entusiastas los ciudadanos previsores que integren esta gran milicia civil; reserva y tesoro de virtudes y energías que la Patria y la sociedad pueden necesitar algún día.

¡Viva España! ¡Viva el Rey! ¡Viva la paz social!

Miguel Primo de Rivera Madrid, 25 de abril de 1926

Sr. don José Maria López Aralos. Iglesias, 26

5.4.-Documento $N^{\circ} 4$

COMANDANCIA GENERAL DE LOS SOMATENES ARMADOS DE MELILLA Y SU TERRITORIO

Orden General del día 6 de septiembre de 1928

Debiendo celebrarse el próximo día 9 del corriente a las 19,30 del mismo, la mánifestación de adhesión al Excmo. Señor Teniente General Marqués de Estella, creador de los somatenes armados de España, por la obra regeneradora llevada a cabo por el Directorio Militar primero y continuada después por el actual Gobierno, todos los Españoles en general y en particular los somatenes, que en todo momento han de dar ejemplo de las más altas virtudes ciudadanas, estamos obligados a prestar nuestro concurso a un acto que como el que se prepara atestigue nuestro agradecimiento al salvador de la Patria.

Fundado en estas razones me dirijo a Vd. invitándole al referido acto, al cual no dudo prestará su concurso.

El somaten de Melilla formará con distintivo de solapa y brazalete, sin armas, en la calle del Duque de Almodóvar.

La bandera de la institución será llevada por el somatenista abanderado don Jaime Tur y Mary acompañado de la escolta correspondiente.

\author{
El Comandante General \\ Manuel González Carrasco
}




\section{Orden General}

Anunciada la llegada a esta Plaza de SS. MM. los Reyes de España y del Presidente del Consejo de Ministros Excmo. Sr. General don Miguel Primo de Rivera, el próximo viernes día 7 del actual, a las cuatro de la tarde, el Somatén Armado de esta Ciudad, tiene el deber de tributar a tan augustas personas el más ferviente testimonio de adhesión, respeto y cariño a los Representantes de la Nación, por cuyo motivo he tenido a bien disponer, que esta honrosa Institución, forme el indicado día, al objeto mencionado, dando con ello una prueba más del patriotismo de todos sus afiliados.

A tal fin, le ruego encarecidamente se sirva concurrir a las tres de la tarde al Muro X del referido día 7, en cuyo lugar se reunirá el Somatén de se Distrito, lugar señalado por el Excmo. Sr. Comandante General del Territorio, para que forme el Somatén Armado.

A dicho acto concurrirá con el fusil, y distintivos de solapa y brazal, ostentando si está en posesión de ella la Medalla de Homenaje a los Reyes.

Tratándose de un acto como el mencionado, al que se asociará toda la población, espero de su celo y amor a esta Institución, su más puntual asistencia, con la cual se pondrá de manifiesto el cariño que hacia sus amados Reyes sienten los Somatenistas de Melilla.

Melilla, 4 de octubre de 1927

El Comandante General Manuel González Carrasco

Sr. Don José Maria López Avalos

Somatén del 1..$^{\circ}$ Distrito.- Calle de Iglesia, 24. 